\title{
QUE HORAS ELA VOLTA? \\ A SUBALTERNIDADE DO EMPREGO DOMÉSTICO E A DIFERENCIAL DISTRIBUIÇÃO DA PRECARIEDADE NA VIDA DAS MULHERES
}

\author{
QUE HORAS ELA VOLTA? \\ THE SUBORDINATION OF DOMESTIC EMPLOYMENT AND THE \\ DIFFERENTIAL DISTRIBUTION OF PRECARIOUSNESS IN WOMEN'S LIVES
}

\author{
${ }^{1}$ Luciana Alves Dombkowitsch, \\ ${ }^{2}$ Renato Duro Dias
}

\section{RESUMO}

Este estudo problematiza a subalternidade do emprego doméstico e a diferencial distribuição da precariedade na vida das mulheres, tendo como ponto de partida o filme QUE HORAS ELA VOLTA? A obra fílmica traduz narrativas de vida de mulheres brasileiras que partem em busca de seus sonhos profissionais, no caso o trabalho doméstico, em detrimento de seus afetos e desejos. Utilizou-se de abordagem qualitativa com ênfase nos estudos culturais feministas. Assim, a investigação pretende avançar nos debates sobre estudos de gênero, como urgentes demandas que se encontram nos corpos de mulheres, cuja invisibilidade e o silêncio se perpetuam histórica e socialmente.

Palavras-chave: emprego doméstico; precariedade; gênero; mulher

\begin{abstract}
This study questions the subordination of domestic employment and the differential distribution of precariousness in the lives of women, taking as its starting point the film QUE HORAS ELA VOLTA? The filmic work reflects life narratives of Brazilian women who leave in search of their professional dreams, where domestic work, at the expense of their affections and desires. Used a qualitative approach with emphasis on cultural feminist studies. Thus, the research aims to advance the discussions on gender studies as urgent demands found in the bodies of women, whose invisibility and silence perpetuate historical and socially.
\end{abstract}

Keywords: domestic employment; precariousness; genre; woman

\footnotetext{
${ }^{1}$ Mestranda em programa de pós-graduação em Direito e Justiça Social pela Universidade Federal do Rio Grande (Furg) Rio Grande, Rio Grande do Sul, Brasil. Email: lucianadomb@ vetorial.net

${ }^{2}$ Doutor e professor do programa de pós-graduação em Direito e Justiça Social pela Universidade Federal do Rio Grande (Furg) Rio Grande, Rio Grande do Sul, Brasil. Email: renatodurodias@gmail.com
} 


\section{INTRODUÇÃO}

Este estudo tem como objetivo problematizar a subalternidade do emprego doméstico e a diferencial distribuição da precariedade na vida das mulheres, tendo como ponto de partida o longa-metragem brasileiro QUE HORAS ELA VOLTA $?^{3}$, filme que conta a história da pernambucana $\mathrm{Val}$, que na procura de melhores condições de vida se muda para São Paulo, deixando para trás a filha Jéssica. A obra traduz histórias e narrativas de vida de inúmeras mulheres brasileiras que partem em busca de seus sonhos profissionais em detrimento de seus afetos e desejos, em negação a sua própria autonomia.

O filme aborda questões absolutamente contemporâneas ao cotidiano da mulher brasileira, uma vida marcada pela subordinação, dependência, desigualdade nas relações laborais, negação da sua sexualidade e do desejo, mas, sobretudo, expõe a face mais perversa de um modelo de sociedade neoliberal, que agravada pelos conflitos de classe, gêneros, raças e sexualidades, precariza vidas de mulheres em espaços urbanos violentos, segregando-as e subalternizando-as em modelos de espoliação laboral-corporal.

Para esta investigação, utilizou-se de abordagem qualitativa com ênfase nos estudos culturais feministas de Butler (2014; 2015), Lagarde (2015) e Spivak (2010). Ancora-se ainda, nos apontamentos de Foucault $(2014 ; 2015)$, nas discussões sobre direitos humanos de Escrivão Filho e Sousa Júnior (2016) e Lucas (2013) e nos debates em direito do trabalho de Delgado e Delgado (2016). Ademais, para análise e discussão imagética, aborda-se os estudos de Marcondes (2013), Aumont (2004) e Dias (2015; 2016).

Propõe-se, como estrutura desta investigação, descrever a obra cinematográfica, historicizar o percurso das relações de trabalho do empregado doméstico, tendo como referência o Brasil colônia, bem como suas intrincadas redes construídas ao longo dos anos no direito brasileiro. Logo a seguir, discute-se o trabalho como direito humano, dando-se posterior ênfase às relações de subalternidade das mulheres no trabalho doméstico precarizante.

\footnotetext{
${ }^{3}$ Filme brasileiro, dirigido por Anna Muylaert, lançado pela Paris Filmes, em 27 de agosto de 2015. Elenco: Regina Casé, Camila Márdila, Michel Joelsas entre outros.
} 
Para além de problematizar a subalternidade do emprego doméstico e a diferencial distribuição da precariedade na vida das mulheres, este estudo pretende avançar nos debates sobre estudos de gênero, cuja ênfase se enquadra no campo das desigualdades e déficits de reconhecimento.

Espera-se que estes diálogos aqui apresentados, sirvam como elementos potencializadores e de desvelamento das urgentes demandas que se encontram nos corpos, nas vidas e narrativas de milhares de mulheres brasileiras, cuja invisibilidade e o silêncio se perpetuam histórica e socialmente.

\section{INTER-RELAÇÕES ENTRE DIREITO, FILOSOFIA E CINEMA: QUE HORAS ELA VOLTA?}

O longa-metragem brasileiro QUE HORAS ELA VOLTA $?^{4}$, conta a história da pernambucana $\mathrm{Val}$, que na procura de melhores condições de vida se muda para São Paulo, deixando para trás sua filha Jéssica. Com muito receio, Val deixa a filha no interior de Pernambuco e parte para ser babá de Fabinho, morando integralmente na casa de seus patrões.

Conforme narrado na sinopse do filme, Val é uma empregada doméstica que mora na casa de seus empregadores há mais de 13 anos, mas que nunca teve a possibilidade de trazer sua filha para morar na casa dos patrões. Treze anos depois, quando o filho dos patrões vai prestar vestibular, Jéssica lhe telefona, pedindo ajuda para ir a São Paulo, no intuito de prestar a mesma prova. Os chefes de Val recebem a menina de braços abertos, só que quando ela deixa de seguir certo protocolo, circulando livremente, como não deveria, a situação se complica. $^{5}$

Val é empregada doméstica na casa da família de classe média de Bárbara (progenitora de Fabinho e principal gestora da residência). A relação "familiar" estampada no filme encobre vários marcadores de diferenças, como a questão de gênero, de classe, de cultura (Val

\footnotetext{
${ }^{4}$ Filme brasileiro, dirigido por Anna Muylaert, lançado pela Paris Filmes, em 27 de agosto de 2015. Elenco: Regina Casé, Camila Márdila, Michel Joelsas entre outros.

${ }^{5}$ Sinopse do filme "QUE HORAS ELA VOLTA?", extraído do site http://www.adorocinema.com/filmes/filme231230/
} 
é nordestina), que se constituem em pilares da construção jurídica do emprego doméstico no Brasil.

A partir da obra cinematográfica analisada, é possível refletir a relação entre direito e cinema, já que o Direito constrói discursivamente os mais diversos campos sociais, neste caso mais específico, o das relações de trabalho e o cinema, que por sua vez, é capaz de desvelar os conflitos sociais, desnudando as desumanidades e as subalternidades que produz, especialmente no que se refere, no caso em análise, das relações de trabalho doméstico, onde podemos ver acentuada a precariedade na vida das mulheres.

A arte possui uma função social, pois permite a experimentação de sensações e
situações não imaginadas pelo indivíduo. Ela recria a história e os anseios humanos.
Ela é uma forma de expressar estilos, expressões verbais de pensamento e encontrar
prazer, além de também poder evidenciar sinais da evolução social.
(MARCONDES, 2013, p. 32)

QUE HORAS ELA VOLTA? apresenta uma crítica ao direito e à sociedade brasileira, que mesmo após a abolição da escravidão, manteve o trabalho doméstico acorrentado a uma legislação atrelada a uma episteme de servidão. O caráter servil do trabalho doméstico no Brasil fica evidente no filme, quando a filha de Val sai do nordeste e vai para São Paulo em busca da ajuda da mãe. Jéssica é um dos elementos de tensão na narrativa, uma vez que passa a questionar a servidão naturalizada de sua mãe, que se incomoda, quando a filha passa a ocupar um espaço que não é seu.

Jéssica, rompendo com as amarras de uma servidão laboral, entra na piscina da família dos patrões e neste momento fica escancarada a servidão naturalizada de Val e sua subalternidade. Esta subalternidade se invisibiliza com as frases pronunciadas, especialmente por Bárbara, afirmando que a empregada é parte da família. No contexto da trama, produz-se uma gama ações e narrativas que confirmam a precariedade das relações laborais de Val.

Este filme traduz essas representações sociais, aliais, o cinema proporciona que o contexto social e político dialogue com milhares de pessoas e que, a partir dessa fala, possa-se implementar mudanças sociais e, consequentemente, no direito. Já que de acordo com Dias 
interdisciplinar, os estudos através das imagens rompem com os recortes epistêmicos e com decisões compartimentadas, produzem-se, assim, infinitas combinações e desdobramentos (DIAS, 2015, p. 477)

Podemos dizer, conforme Marcondes (2013), que o cinema gera espaço de construção da ciência jurídica, constituindo-se num campo de discussão e de problematização das questões sociais.

\begin{abstract}
A análise iconográfica trata de imagens, estórias e representações ao invés de motivos, desta forma, ela pressupõe muito mais que a familiaridade com objetos e fatos que se adquirem a partir de uma experiência vivida (PANOFSKY, 1986), por outro lado a análise iconológica necessita escavar quais os símbolos percorreram o autor da imagem. (DIAS, 2016, p. 269)
\end{abstract}

\title{
3. O EMPREGADO DOMÉSTICO: UMA HERANÇA COLONIALISTA
}

Compreender como se deu a proteção ao trabalhador doméstico, em especial, a relativa ao empregado doméstico no Brasil, demanda igual compreensão da origem desse indivíduo trabalhador, origem essa marcada pelo tratamento discriminatório e pela segregação social originada desde a servidão e continuada na escravidão. A problematização desse tratamento discriminatório tradicionalmente dispensado ao empregado doméstico é ponto de partida relevante para entender as atuais controvérsias sobre as questões que circundam a proteção que a ele deve ser dispensada.

O processo de colonização pelo qual foi submetido o Brasil nos deixou um extenso legado de discriminação e de injustiças sociais, especialmente no que se refere aos povos indígenas e aos descendentes de africanos trazidos forçadamente para o Brasil. De uma sociedade escravocrata ganhamos o legado do trabalho servil dos empregados domésticos e dos trabalhadores rurais e, essa realizada, fica patente diante da realidade nua e crua de ausência de direitos a essas espécies de trabalhadores, que embora muitas vezes tenham alçado a categoria de empregados, não obtiveram a mesma sorte de direitos das demais classes de trabalhadores empregados.

[...], o elevado grau de injustiça social vivenciado na atualidade pelos brasileiros deflui, em grande parte, do próprio processo de desenvolvimento do país. (...) Desse modo, a sociedade escravocrata instituída e difundida durante todo o período colonial foi responsável pelos altos índices de preconceito e discriminação racial em relação à população indígena e aos descendentes dos escravos africanos. (SPAREMBERGER, 2011, p. 131) 
A compreensão acerca das injustiças sociais, potencializadas pelo discurso jurídico que legitima e naturaliza a ideia de que o empregado doméstico é parte da família, tirando dele qualquer possibilidade de fala ou de circulação, até hoje persegue essa espécie de trabalhador, envolvendo por óbvio, considerações sobre as condições históricas, sociais e culturais que moldaram a classe a que ele pertence, em particular no Brasil. Com efeito, verifica-se que a discriminação jurídica dispensada ao doméstico possui raízes culturais profundas que o direito, sozinho, não dará respostas.

Pode-se dizer, segundo Escrivão Filho e Sousa Júnior (2016), que os empregados domésticos viveram (e ainda vivem), uma história de ausências vividas em um mundo de opressão e de exploração social e econômica típicas da formação da sociedade brasileira. Os autores, fazendo uma alusão à sociologia das ausências de Boaventura de Sousa Santos, apontam que o colonialismo instituído e desenvolvido na América Latina e em especial no Brasil, produziu um processo social de negação do outro:

Uma história de ausências produzidas em um cotidiano de opressão e exploração,
repleta de experiências desperdiçadas pelo colonialismo instituído e desenvolvido
como processo social de negação do "outro", e pela colonialidade que ainda hoje se
manifesta em diversas dimensões da sociedade brasileira, demarcada pelas
condições do patrimonialismo, patriarcado e racismo características da formação
econômica, social, política e cultural do Brasil. (ESCRIVÃO FILHO e SOUSA
JÚNIOR, 2016, p. 74)

O colonialismo a que se referem os autores corresponde a uma forma de dominação e exploração não só política, mas principalmente econômica que teve como origem o processo de colonização do território brasileiro pelos europeus sobre os povos daqui originários e ainda sobre os povos africanos que trouxeram forçadamente para trabalharem como escravos. Esse colonialismo que se globalizou não se reduz apenas a expansão territorial de sua origem, mas, sobretudo, segundo Escrivão Filho e Sousa Júnior (2016), manifesta-se em todos os campos sociais, em todos os planos, meios e dimensões, produzindo e reproduzindo os sujeitos de dominação.

É certo que as relações de colonialidade que se vivenciam hoje no âmbito das relações sociais não são mais aquelas típicas da metrópole/colônia, mas sim um colonialismo, no dizer de Escrivão Filho e Sousa Júnior (2016), mais fluído, globalizado. No entanto, é impossível 
não dizer, que as relações de colonialidade desenvolvidas no Brasil deixaram marcas profundas no âmbito das relações sociais e culturais e que também, sem dúvidas, foram determinantes na construção do direito brasileiro, especialmente no que se refere aos grupos periféricos como o dos empregados domésticos.

Que dizer da sua concepção acerca de camponeses e sobretudo indígenas e quilombolas, senão que a colonialidade da cultura, do saber e do poder institucional produziram violenta e simbolicamente ao longo da história e sua ausência nos espaços de poder, e o desperdício de suas expressões culturais e de conhecimento, relegando-os a uma permanente situação de degredo e desprestígio social que acabam por se reproduzir também em outros preconceitos de raça, gênero, orientação afetiva na sociedade brasileira? (ESCRIVÃO FILHO e SOUSA JÚNIOR, 2016, p. 77)

Segundo Delgado (2016), a década de 30, marcada pelas grandes insurgências do movimento operário no Brasil por melhores condições de trabalho e de vida, foi a época de maior expansão do Direito do Trabalho no Brasil. No entanto, as diferenças sociais ficavam cada vez mais largas, aprofundando as injustiças sociais. Nesse processo de expansão do neoliberalismo econômico, surge a CLT (Consolidação das Leis do Trabalho), aprovada pelo Decreto-Lei n. 5.452 , de $1^{\circ}$ de maio de 1943, tendo papel de destaque, ao lado de inúmeros outros diplomas legais esparsos complementares, que foram instituídos nos anos e décadas subsequentes a 1943, com o intuito de acalmar os movimentos de trabalhadores.

No entanto, ainda como uma herança do colonialismo ocidental, dois grandes grupos de trabalhadores empregados ficaram de fora dessa regulamentação, ou seja, mantiveram-se excluídos, à margem desse processo de integração jurídico-trabalhista dos anos 1930: os empregados domésticos e os trabalhadores rurais. A fase de inclusão jurídica da categoria doméstica no Direito do Trabalho brasileiro ostenta dois momentos extremamente diversos: o período pré-Constituição de 1988 e o período inaugurado com a Constituição de 1988.

Assim é possível dizer que a libertação de cativos no Brasil, no final do século XIX, embora carregue uma dimensão jurídica de liberdade, essa liberdade traz consigo apenas um reconhecimento institucional da liberdade, restringindo-se, conforme Escrivão Filho e Sousa Júnior (2016), a uma abolição jurídica da escravidão, sem que com ela fossem implementadas políticas capazes de estender direitos econômicos, sociais, culturais e étnicos capazes de 
romper com uma herança de quatro séculos de escravidão, fazendo perpetuar ainda hoje, as velhas estruturas coloniais e dominação.

\section{O EMPREGADO DOMÉSTICO NA PERSPECTIVA DO DIREITO BRASILEIRO}

O trabalho doméstico foi tratado pelo ordenamento jurídico brasileiro pela primeira vez em 30/07/1923, através do Decreto n. ${ }^{\circ} 16.107$, o qual regulamentava a locação de serviços domésticos no Brasil, até então, era-lhe aplicados os preceitos do código civil de 1916, no que dizia respeito à locação de serviços. O Decreto 16.107 fazia alusão ao locador de serviços domésticos, nunca sendo o mesmo designado como trabalhador ou como empregado. Apenas em 27/02/1941, com a edição do Decreto-lei $n^{\circ} 3.078$, passou-se a fazer referência ao empregado doméstico.

O artigo primeiro do Decreto-lei 3.078 conceituou quem seriam considerados empregados domésticos, quais sejam aqueles que, de qualquer profissão ou mister, mediante remuneração, prestem serviços em residências particulares ou a benefício destas. No entanto, pequeno foi o rol dos direitos reconhecidos a esta categoria de trabalhadores, haja vista que ao contrato de trabalho não foi reconhecido o estatuto de contrato de emprego, continuando com o caráter de contrato de locação adquirido com o Decreto n. ${ }^{\circ} 16.107 / 1923$, o que se pode constatar pelo conteúdo do artigo $3^{\circ}$ do Decreto-lei 3.078/1941: “Art. $3^{\circ}$ - O contrato de $\underline{\text { locacão de servico doméstico }}^{6}{ }^{2}$ rescinde-se pela simples manifestação da vontade de qualquer dos contratantes."

O Decreto-lei 3.078/1941, nos parágrafos do artigo $3^{\circ}$, garantiu apenas o direito a aviso prévio de oito dias em caso de uma das partes decidir rescindir o contrato de locação de serviços domésticos após o término do período de experiência de seis meses, antes desse prazo, o contrato poderia ser rescindindo sem qualquer aviso prévio. No entanto, tendo o locatário atentado contra a honra e/ou a integridade física do locador ou tendo deixado de lhe garantir condições higiênicas de alimentação e habitação, poderia o locador, mesmo antes de findo o período de experiência, rescindir o contrato de locação e exigir do locatário o pagamento de oito dias a título de indenização.

\footnotetext{
${ }^{6}$ Grifo nosso.
} 
O Decreto-lei n..$^{\circ} 5.452$, de $1^{\circ}$ de maio de 1943, instituiu a Consolidação das Leis do Trabalho e estatui as normas que regulam as relações individuais e coletivas de trabalho, definindo a partir do artigo $3^{\circ}$ o conceito de empregado, como sendo a pessoa física que presta serviços de natureza não eventual a empregador, sob a dependência deste e mediante salário. A CLT, em uma tentativa de demonstrar um caráter isonômico, estabelece no parágrafo único do referido artigo, que não haverá distinções relativas à espécie de emprego e à condição de trabalhador, no entanto, retira direitos dos empregados domésticos.

No entanto, o que inicialmente parecia se tratar de uma grande conquista dos trabalhadores empregados, sem que a lei lhe impusesse qualquer forma de discriminação, não passou de mera ilusão, posto que, para sepultar qualquer possibilidade de equiparar os empregados domésticos aos demais trabalhadores empregados o Decreto-lei 5.452/43, traz de forma taxativa, em seu artigo $7^{\circ}$, que os preceitos constantes na referida norma, salvo disposição expressamente determinada em contrário, não se aplicam aos empregados domésticos, assim considerados, aqueles que prestam serviços de natureza não-econômica à pessoa ou à família, no âmbito residencial destas.

A justificativa do legislador para impor essa histórica injustiça aos empregados domésticos, segundo Martins (2013) é de que o empregador doméstico não tem por finalidade explorar atividade econômica lucrativa por tratar-se de pessoa ou família e por ser o serviço, prestado para o âmbito da residência destes. O empregado doméstico, precisou então esperar quase trinta anos, para que uma norma jurídica, o Decreto 5.859/72, viesse tratar especificamente do doméstico como empregado, garantindo-lhe então, o direito a férias anuais, minimizando a injustiça de ausência de reconhecimento e de direitos.

No entanto, mesmo tendo o Decreto 5.859/72 reconhecido o direito à férias anuais aos empregados domésticos, não o fez de forma isonômica, haja vista que aos demais empregados era garantido o direito à 30 dias de férias, aos domésticos eram garantidos 20 dias úteis, demonstrando a intenção do legislador em continuar dando tratamento diferenciado ao empregado doméstico. Ademais, como nos informa Martins (2013), o Decreto 5859/73 permitia que o empregado doméstico recebesse salário inferior ao salário-mínimo, não garantia direito à $13^{\circ}$ salário, ao aviso-prévio e ao repouso semanal remunerado, o que somente veio a ser garantido ao doméstico, com o advento da Constituição Federal de 1988. 
A partir da Constituição de 1988, o empregado doméstico teve garantido pelo parágrafo único do artigo $7^{\circ}$, o direito à percepção de salário não inferior ao mínimo nacional; a irredutibilidade de salário, ao $13^{\circ}$ salário, ao repouso semanal remunerado preferencialmente aos domingos, a férias anuais de 30 dias acrescidos de 1/3; à licença à gestante, à licença-paternidade, ao aviso prévio proporcional ao tempo de serviço e à aposentadoria prevista no regime geral de previdência social. Importante destacar que o direito aos feriados foram garantidos apenas em 2006, pela Lei 11.324.

Embora, a Constituição Federal de 1988 represente um marco na ampliação de direitos aos empregados domésticos, estes ainda continuarão à margem de vários outros direitos disponibilizados pela própria Constituição aos demais trabalhadores empregados, inclusive aos rurais, que passam a ser então, abrangidos pela legislação trabalhista. Assim, mesmo após o advento da Constituição de 1988, os empregados domésticos continuarão sem gozar os direitos relativos à proteção contra a despedida arbitrária, ao benefício de seguro-desemprego, ao fundo de garantia por tempo de serviço, à remuneração do trabalho noturno superior ao diurno, ao salário-família, à limitação da duração do trabalho e ao pagamento da jornada extraordinária e adicional de remuneração para atividades insalubres ou periculosas.

Muito embora a OIT tenha, conforme nos demonstra Resende (2013), aprovado em 2011 a Convenção $n^{\circ}$ 189, que trata da igualdade de direitos entre o empregado doméstico e os demais trabalhadores empregados, somente com a Emenda Constitucional $n^{\circ} 72$ de 2013, ou seja, 25 anos depois, da promulgação da Constituição de 1988, que alterou o parágrafo único do artigo $7^{\circ}$, é que os empregados domésticos passaram a ter os direitos sociais trabalhistas previstos no artigo $7^{\circ}$ da Constituição, no entanto, somente com a edição da Lei Complementar $\mathrm{n}^{\circ} 150$ de $1^{\circ}$ de junho de 2015 é que estes direitos passaram a ser exigíveis do empregador doméstico.

Parágrafo único. São assegurados à categoria dos trabalhadores domésticos os direitos previstos nos incisos IV, VI, VII, VIII, X, XIII, XV, XVI, XVII, XVIII, XIX, XXI, XXII, XXIV, XXVI, XXX, XXXI e XXXIII e, atendidas as condições estabelecidas em lei e observada a simplificação do cumprimento das obrigações tributárias, principais e acessórias, decorrentes da relação de trabalho e suas 
peculiaridades, os previstos nos incisos I, II, III, IX, XII, XXV e XXVIII, bem como a sua integração à previdência social. ${ }^{7}$

A Convenção $n^{\circ} 189$ da OIT, aprovada em 2011 trata da igualdade de direitos entre o empregado doméstico e os demais trabalhadores empregados, trazendo um caráter inovador e de extrema relevância para o campo do direito do trabalho, ao determinar a todos os seus membros que adotem medidas para assegurar a promoção e a proteção efetivas dos direitos humanos de todos trabalhadores domésticos, em conformidade com as suas disposições. O reconhecimento de direitos trabalhistas como Direitos Humanos deverá mudar o rumo das discussões acerca dos direitos fundamentais garantidos aos trabalhadores empregados pela Constituição Federal de 1988.

\section{DIREITO HUMANO AO EMPREGO DOMÉSTICO DECENTE}

A dignidade da pessoa humana e os direitos fundamentais previstos na Constituição Federal de 1988 possuem o condão de impor limites a atuação estatal para que o ente público, em todas as suas dimensões, não venha violar a dignidade pessoal. Mas é certo, que a obrigação estatal vai muito mais além do simples ato de abstenção de violação de direitos fundamentais, é tarefa estatal a atuação permanente no sentido de promover "[...] proteção, promoção e realização concreta de uma vida com dignidade para todos.” (Sarlet, 2015, p. 89). Enfim, deve o Estado atuar na elaboração de uma política da dignidade da pessoa humana, capaz de garantir o pleno desenvolvimento da personalidade de cada indivíduo.

[...] sustenta-se, com razão, que a concretização do programa normativo do princípio da dignidade da pessoa humana incumbe aos órgãos estatais, especialmente, contudo, ao legislador, encarregado de edificar uma ordem jurídica que atenda às exigências do princípio. Em outras palavras - aqui considerando a dignidade como tarefa -, o princípio da dignidade da pessoa humana impõe ao Estado, além do dever de respeito e proteção, a obrigação de promover as condições que viabilizem e removam toda sorte de obstáculos que estejam a impedir as pessoas de viverem com dignidade. (SARLET, 2015, p. 90)

Ainda pode-se dizer, que para além das obrigações estatais, em especial as do poder legislativo, contribui significativamente Sarlet (2015), quando traz à discussão a necessidade da vinculação da ordem comunitária na obrigação de promoção e de garantia da dignidade, uma vez que, tanto particulares quanto entidades privadas estão diretamente vinculadas ao

\footnotetext{
${ }^{7}$ Parágrafo único com redação determinada pela Emenda Constitucional n. 72 de 02/04/2013.
} 
cumprimento dos direitos fundamentais. Moraes (2006), propõe uma análise do princípio da dignidade, a partir de um desdobramento deste princípio em quatro postulados, o da igualdade, o da integridade física e moral, o da liberdade e o da solidariedade, este último, de extrema relevância, posto que vincula todos os membros da comunidade humana, uma vez que a dignidade implica um dever de solidariedade.

No entanto, a implementação do princípio da dignidade da pessoa humana assim como os deveres de solidariedade que lhe é inerente, tanto pelo Estado quanto pela ordem comunitária, encontram um óbice, impedindo a sua realização, posto que incompatíveis com uma ordem social marcada pela opressão socioeconômica típica do capitalismo globalizado, que só tem tido como retorno de suas políticas econômicas e sócias nefastas, o incremento assustador dos níveis de exclusão política, social e econômica. As relações de trabalho pautadas em políticas de Estado neoliberais só tem produzido precariedade na vida dos trabalhadores, em especial dos empregados domésticos.

O que se verifica é uma subversão do estado democrático e constitucional de direito, especialmente em países periféricos como Brasil, convertendo-se em um estado neocolonial, aonde se pode constatar como resultado, a desnacionalização das riquezas nacionais e consequentemente a perda da soberania estatal em favor do capital estrangeiro, das grandes corporações, inviabilizando assim, a implementação de políticas sociais que visem a efetivação de direitos humanos fundamentais e da realização da justiça social.

Notadamente sabe-se, que a Constituição Federal de 1988 trouxe uma mudança de paradigma, alçando os direitos trabalhistas ao estatuto de direitos sociais fundamentais, trazendo em seu artigo sétimo uma extensa lista de direitos conferidos aos trabalhadores urbanos e rurais, direitos estes já previstos na legislação pátria a partir de vários dispositivos legais, com ênfase no Decreto-lei 5.452/43. No entanto, uma injustiça não foi reparada pela carta constitucional, uma vez que manteve fora de sua proteção integral os empregados domésticos.

Em junho de 2011 ocorreu a 100 a Conferência Internacional do Trabalho, onde foi realizada a discussão acerca do trabalho decente para os trabalhadores e trabalhadoras 
domésticas, do qual resultou a edição da Convenção $\mathrm{n}^{\circ} 189$ da OIT, denominada de convenção sobre o trabalho decente para as trabalhadoras e os trabalhadores domésticos, vigente desde setembro de 2013. Um dos principais objetivos desta convenção é a de alcançar a todos os trabalhadores e trabalhadoras os objetivos da declaração da OIT sobre direitos fundamentais do trabalho e da declaração da OIT sobre justiça social, uma vez que o trabalho doméstico, principalmente nos países periféricos, tem como característica a discriminação em ralação as condições de emprego e trabalho, configurando claro abuso aos direitos humanos.

O artigo $3^{\circ}$ da Convenção 189 da OIT - determina que todo membro deverá adotar medidas para assegurar a promoção e a proteção efetivas dos direitos humanos de todos os trabalhadores domésticos, e para respeitar, promover e tornar realidade os princípios e direitos fundamentais no trabalho, dentre eles a eliminação de todas as formas de trabalho forçado e obrigatório, a erradicação do trabalho infantil e a eliminação da discriminação em matéria de emprego e ocupação. $\mathrm{O}$ artigo $5^{\circ}$ prevê a todos os membros, que deverão adotar todas as medidas necessárias para assegurar efetiva proteção aos trabalhadores e trabalhadoras domésticas contra todas as formas de abuso, assédio e violência.

Enfim, segundo a convenção 189 da OIT, todos os países membros, deverão adotar medidas para assegurar que aos trabalhadores e trabalhadoras domésticas, sejam assegurados os mesmos direitos dos trabalhadores em geral, afim de que usufruam de condições equitativas de emprego e condições de trabalho decente, como forma de efetivação de direitos humanos fundamentais. Dessa forma, resta clara a natureza de direitos humanos atribuída aos direitos fundamentais estendidos aos trabalhadores e trabalhadoras domésticas a partir da Emenda Constitucional 72/2013.

No entanto, difícil esquecer da herança colonial e da presente colonialidade onde se constituem as identidades dos trabalhadores e das trabalhadoras domésticas, posto que segundo Escrivão Filho e Sousa Junior (2016), foram considerados escravos até o ano de 1888, 64 anos depois da primeira constituição brasileira, a qual foi fundada nos princípios inerentes aos direitos dos homens oriundos do pensamento liberal deflagrado pela Declaração dos Direitos do Homem e do Cidadão, no entanto, a existência de um direito material-formal segundo o qual os homens nasciam livres, os trabalhadores e trabalhadoras continuaram a ser vendidos como coisas. 
Foram necessários 127, da abolição da escravidão em 1888 à Lei Complementar 150/2015, para que trabalhadores e trabalhadoras domésticas passassem a ter os mesmos direitos que os demais trabalhadores, corroborando com o entendimento de que fomos e somos constituídos dentro de uma sociedade colonialista, posto que, apesar de todos os componentes jurídico-formais, seja a Declaração dos Direitos do Homem e do Cidadão de 1789, seja a Declaração Universal dos Direitos Humanos de 1948, continuamos ignorando esses trabalhadores, que são constituídos na sua ampla maioria por mulheres, como humanos.

Para Lucas (2013), a validade dos direitos humanos não se encontram apenas no fato de serem ou não serem reconhecidos institucionalmente, mas “[...] na reciprocidade moral que obriga mutuamente todos os homens e que se torna condição de possibilidade para a existência humana individual e coletiva." (Lucas, 2013, p. 47). Por essa razão, diz que, mesmo sendo unânime o desejo da sociedade mundial de que os direitos humanos passem a fazer parte de todas as agendas nacionais no sentido de promoverem uma transformação radical da realidade de todos aqueles que necessitam de proteção e de preservação da dignidade, esse reconhecimento não se dá de maneira uniforme em todos os países.

Condições econômicas, culturais, políticas, etc., interferem na forma como cada país
estabelece sua política de direitos humanos. Esse quadro de diversidades não
representa outra coisa senão as diferenças históricas que caracterizam a formação, o
desenvolvimento e a expectativa de cada nação em relação ao seu passado, presente
e futuro. Nesse caso, o fator histórico é, inclusive, como no caso de muitos países do
Terceiro Mundo, responsável pela dificuldade em se garantir plenamente os
referidos direitos, configurando-se uma herança social que o povo, de um modo
geral, pretende superar. (LUCAS, 2013, p. 45-46)

A invisibilidade, a ausência de fala, são elementos constituinte da subalternidade dessa categoria de trabalhadores, que vêem a precariedade de suas vidas serem maximizadas diante de componentes como a sua cor, a sua classe social e a sua identidade de gênero, todos esses elementos decorrem, certamente de condições históricas e culturais que impossibilitam a garantia plena dos direitos humanos às trabalhadoras empregadas domésticas. 


\section{CONSIDERAÇÕES FINAIS}

A legitimação das estruturas do funcionamento legal da legislação trabalhista, de perpetuação de ausências de direitos plenos aos trabalhadores e trabalhadoras domésticas, é a demonstração efetiva do que Spyvak (2010) denomina de violência epistêmica caracterizada por um projeto legal neocolonialista de ausência de representação legal e política do sujeito subalterno, uma vez que esse sujeito subalterno se encontra impossibilitado de articular um discurso de resistência que esteja fora dos discursos hegemônicos.

Para Spyvak (2010), se o discurso do subalterno é eliminado, suprimido, o da mulher subalterna encontra-se em uma posição ainda mais periférica, dado os problemas relacionados às questões de gênero, sendo colocado, dentro do contexto da produção colonial dos discursos, numa posição ainda mais profunda de obscuridade.

É mais uma questão de que, apesar de ambos serem objetos da historiografia colonialista e sujeitos da insurgência, a construção ideológica de gênero mantém a dominação masculina. Se, no contexto da produção colonial, o sujeito subalterno não tem história e não pode falar, o sujeito subalterno feminino está ainda mais profundamente na obscuridade. (SPYVAK, 2010, p. 66-67)

Quando se fala em neocolonialismo, está também se referindo a problemática da divisão internacional do trabalho contemporâneo, colocando de uma lado, um grupo de países, em sua maioria de primeiro mundo, aptos a investir seu capital em países de terceiro mundo, que reconhecidamente possuem um campo fértil para esse tipo de investimentos, dada a sua característica consumista e da existência de uma vasta mão de obra, mal protegida e mutável.

Pode-se dizer, que se trata de um verdadeiro processo de colonização da mão de obra de terceiro mundo. Desta forma, a autora, critica as teorias de divisão internacional do trabalho ao reduzirem o problema da mão de obra ao barato ou ao caro, posto que entende, que a subalternidade dos trabalhadores se encontra na ausência de proteção legal, situação esta, que se coaduna perfeitamente ao problema do trabalho doméstico subalternizado, "O trabalho humano não é intrinsecamente "barato" ou "caro". É assegurado por uma ausência de leis de trabalho (ou sua execução discriminatória), [...].” (SPYVAK, 2010, p. 68)

Neste contexto, o presente trabalho problematiza a concepção de subalternidade a partir de Spyvak, compreendendo que o sujeito subalterno é efeito do "discurso dominante", o 
que propicia o questionamento acerca do discurso que é sempre "sobre" a mulher e, no caso da mulher empregada doméstica é mais intenso, pois concentra-se na construções de papéis do feminino e do masculino, segundo o qual o papel de cuidado é destinado à mulher e a essa mulher que cuida da vida do outro, a pena é o silêncio. Assim, é possível afirmar, dentro de uma perspectiva spivakiana, que a empregada doméstica representa o sujeito subalterno feminino, a qual se encontra em uma condição mais intensa de obscuridade, o que favorece a sua perpetuação.

Pode-se dizer, que a discussão acerca do trabalho doméstico no Brasil, está inserida dentro do que Butler chama de problemas de gênero. Para Butler (2014), os sistemas jurídicos de poder produzem os sujeitos, limitando a vida política dos indivíduos ligados a esta estrutura, ou seja, a formação jurídica da linguagem e da política que representa as mulheres como sujeito é formado através de um discurso que em tese, deveria facilitar a "emancipação" das mulheres, no entanto, se transforma em um sistema que produz esse sujeito dentro de padrões de dominação, contribuindo para o fracasso da tão desejada emancipação.

\begin{abstract}
Não basta inquirir como as mulheres podem se fazer representar mais plenamente na linguagem e na política. A crítica feminista também deve compreender como a categoria das "mulheres", o sujeito do feminismo, é reproduzida e reprimida pelas mesmas estruturas de poder por intermédio das quais busca-se a emancipação. (BUTLER, 2014, p. 19)
\end{abstract}

A partir de Butler pode-se problematizar que tipo de sujeito do feminismo se está querendo construir, no entanto, em primeiro lugar se deve levar em consideração a crítica aos sistemas de poder que constituem esse mesmo sujeito, o qual deverá ser constituído dentro de uma perspectiva que rompa com a identidade rígida deste sujeito, e repense o sujeito do feminismo como um sujeito fluído, que desconstrua toda forma de construção de identidade que oprima as singularidades humanas que diante da rigidez do sujeito do feminismo, se encontram fora do padrão adequado ou correto deste sujeito.

Para Butler (2014), a emancipação das mulheres somente ocorrerá com práticas subversivas que questionem essas relações de poder, que discursivamente constroem as relações de gênero dentro de um padrão binário, onde as categorias homem/mulher, masculino/feminino são colocadas em oposição, constituindo relações sociais hierarquizadas, 
onde a mulher se constitui em posição de inferioridade em ralação ao homem e a elas, são relegadas as condições mais precarizadas de vida e de trabalho.

Nesse contexto, o filme QUE HORAS ELA VOLTA? problematiza, dando visibilidade e fazendo a critica do sujeito subalternizado da empregada doméstica, para a qual não existe espaço de fala, vez que ausentes os espaços de representação política desse sujeito. Para Lagarde (2015), a capacidade de lutar por reconhecimento político e de implementação de mudanças nas relações sociais relacionadas a vida laborativa das mulheres, é a medida mais importante para impor transformações, só que para isso, segundo a autora é indispensável a sensibilidade intelectual e afetiva para se compreender as necessidades das pessoas e dos grupos a partir de uma (re)significação política de gênero.

Ainda sobre a questão do reconhecimento, segundo Butler (2015), para que o sujeito seja reconhecido como sujeito, este deve ter sido constituído por normas que facilitem este reconhecimento, caso contrário teremos sujeitos que não serão reconhecíveis como sujeitos e provavelmente nunca serão reconhecidas como vidas. Dessa maneira, a capacidade de apreender uma vida depende em muito, daquilo que já foi dito, de que o sujeito tenha sido constituído de acordo com as normas que a caracterizam como uma vida, produzindo ainda, um problema ético no que se refere a capacidade de definir o que será reconhecido e o que será, consequentemente passível de ser protegido contra a violência.

A conclusão de que não há vida como não precária, poderia nos levar a pensar que essa condição compartilhada de precariedade conduziria a um reconhecimento recíproco desta condição produzindo um sentimento de solidariedade, no entanto, o resultado decorrente desta condição é justamente o contrário, qual seja, a de "uma exploração específica de populaçõesalvo, de vidas que não são exatamente vidas, que são consideradas "destrutíveis" e "não passíveis de luto". (BUTLER, 2015, p. 53)

Portanto, dizer que a vida é precária traz como compromisso a manutenção dessa vida, o que somente será possível com a implementação de condições sociais e políticas que garantam a existência dessa vida, posto que, “[...] não pode haver nenhuma persistência na vida sem pelo menos algumas condições que tornem uma vida vivível.” (BUTLER, 2015, p. 40). 
Para concluir, segundo Butler (2015), deve-se ter responsabilidade moral e ética para construir uma crítica social que busque a criação de condições sociais e econômicas pautadas em sentimentos de afetividade, os quais possibilitarão desenvolver sentimentos de comoção perante a violência e as mais diversas formas de violação da vida. Quando o outro se comove com o sofrimento e com a condição maximizada da precariedade da vida do outro, este sujeito passa a reconhecido como uma vida a ser vivida de forma a minimizar a sua precariedade.

\section{REFERÊNCIAS}

BRASIL. Códigos 4 em 1 Saraiva: CLT, CPC, Legislação Previdenciária / obra coletiva de autoria da Editora Saraiva com a colaboração de Luiz Roberto Curia, Lívia Céspedes e Fabiana Dias da Rocha. - 11 a ed. - São Paulo: Saraiva, 2016.

BUTLER, Judith. Problemas de gênero: Feminismo e subversão da identidade. $7^{\mathrm{a}}$ ed. Rio de Janeiro: Civilização Brasileira, 2014.

BUTLER, Judith. Quadros de Guerra - quando a vida é passível de luto? $1^{\text {a }}$ ed. Rio de Janeiro: Civilização Brasileira, 2015.

DELGADO, Mauricio Godinho e DELGADO, Gabriela Neves. O novo manual do trabalho doméstico - São Paulo : LTr, 2016.

DIAS, Renato Duro. Interdição de gênero: a lei que silencia o corpo. In: Direito, arte e literatura [Recurso eletrônico on-line] organização CONPEDI/UFMG/FUMEC/ Dom Helder Câmara. Florianópolis: CONPEDI, 2015.

Fluxos migratórios e fronteiras: necessárias aproximações entre arte política e direito. In: Direito, arte e literatura [Recurso eletrônico on-line] organização CONPEDI/UnB/UCB/IDP/ UDF. Florianópolis: CONPEDI, 2016.

ESCRIVÃO FILHO, Antônio; SOUSA JUNIOR, José Geraldo de. Para um debate teóricoconceitual e político sobre os direitos humanos - Belo Horizonte: Editora D’Plácido, 2016. 
FARIAS, Vilson. Os direitos e deveres do empregado e do empregador doméstico à luz da emenda constitucional $n .^{\circ} 72 / 2013$ (com incursão no direito comparado): aspectos materiais, processuais e sociológicos - Pelotas: Editora Livraria Mundial, 2014.

FOUCAULT, Michel. História da Sexualidade 1: A vontade de saber. - São Paulo: Paz e Terra, 2014.

FOUCAULT, Michel. Microfísica do Poder. - 2ª ed. Rio de Janeiro: Paz e Terra, 2015.

GARCIA, Gustavo Filipe Barbosa. Manual de Direito do Trabalho - $7^{\mathrm{a}}$ ed. - Rio de Janeiro: Forense; São Paulo: Método, 2015.

LAGARDE, Marcela. Claves feministas para mis sociais de la vida. - Ciudad Autónoma de Buenos Aires: Diego Pérez Roig, 2015.

LUCAS, Doglas Cesar. Direitos Humanos e Interculturalidade: um diálogo entre igualdade e diferença. - 2a ed. - Ijuí: Editora Unijuí, 2013.

MARCONDES, Thereza Cristina Bohlen Bitencourt. Cine Igualdade: A evolução do cinema LGBT e a conquista de direitos - Belo Horizonte: Editora D’Plácido, 2013.

MARTINS, Sérgio Pinto. Direito do Trabalho - 22ª ed. - São Paulo: Atlas, 2006.

Sérgio Pinto. Direito do Trabalho - 30 ed. - São Paulo: Atlas, 2013.

MORAES, Maria Celina Bondin. O conceito da dignidade humana: substrato axiológico e conteúdo normativo. In. SARLET, Ingo Wolfgang, org. Constituição, direitos fundamentais e direito privado. 2. ed., rev. e ampl. Porto Alegre: Livraria do Advogado, 2006. p. 107-149.

NERY JUNIOR, Nelson e NERY Rosa Maria de Andrade. Constituição Federal Comentada e legislação constitucional. - São Paulo: Editora Revistas dos Tribunais, 2006.

OIT. Convenção e Recomendação sobre Trabalho Decente para as Trabalhadoras e os Trabalhadores Domésticos.

Disponível em: 
http://www.oit.org.br/sites/default/files/topic/housework/doc/trabalho_domestico_nota_5_565 .pdf. acesso 13/04/2016.

RESENDE, Ricardo. Direito do Trabalho esquematizado - $3^{\mathrm{a}}$ ed. - Rio de Janeiro: Forense; São Paulo: Método, 2013.

RODRIGUES, Adroaldo Júnior Vidal ... [et al.]; coordenadora Luciane Cardoso Barzotto. Trabalho e igualdade: tipos de discriminação no ambiente de trabalho. - Porto Alegre: Livraria do Advogado; Escola Judicial do TRT da 4a R., 2012.

SANTOS, Reinaldo. Empregado domésticos: respostas a perguntas: legislação, direitos da nova Constituição - 12a ed. - Rio de Janeiro: Edições Trabalhistas, 1998.

SARLET, Ingo Wolfgang. Dignidade (da Pessoa) Humana e Direitos Fundamentais de 1988 - $9^{a}$ ed. - Porto Alegre: Livraria do Advogado, 2012.

SARLET, Ingo Wolfgang; MELLO FILHO, Luiz Philippe Vieira de e FRAZÃO, Ana de Oliveira. (coordenadores) Diálogos entre o direito do trabalho e o direito constitucional: estudos em homenagem a Rosa Maria Weber - São Paulo: Saraiva, 2014.

SPAREMBERGER, Raquel Fabiana Lopes. Antropologia e diferença: quilombolas e indígenas na luta pelo reconhecimento do seu lugar no Brasil dos (Des)iguais. In. COLAÇO, Thais Luzia. Elementos de Antropologia Jurídica - São Paulo: Conceito Editorial, 2011.

SPYVAK, Gayatri Chakravorty. Pode o Subalterno Falar? - Belo Horizonte: Editora UFMG, 2010.

VIEIRA, Tereza Rodrigues; CARDIN, Valéria Silva Galdino e GOMES, Luiz Geraldo do Carmo. (organizadores). Bioética e Cinema. - Maringá: Editora Miraluz, 2016. 